\title{
Experimental investigation of thermoelectric cooling system with heat recovery
}

\author{
Justyna Gołębiowska ${ }^{1, *}$, and Agnieszka Żelazna ${ }^{1}$ \\ ${ }^{1}$ Lublin University of Technology, Faculty of Environmental Engineering, Institute of Renewable \\ Energy Engineering, ul. Nadbystrzycka 40B, 20-618 Lublin, Poland
}

\begin{abstract}
Thermoelectric modules are implements used as power generators and cooling devices. In case of TE module application for space cooling, it is highly recommended to reuse energy generated on the hot side of the module for example for domestic water heating. In this paper, an example of a small scale thermoelectric cooling system with heat recovery was presented. In the tested system, the performance of TE module was supported by two heat exchangers. On the cold side of the TE module the forced convection was provided by the implementation of aluminium heat sink integrated with fan. On the hot side a water heat exchanger was built in order to reuse waste energy to heat water in the water tank. Different values of current were applied to the TE module to observe the differences in the module performance. The correlation between the air temperature inside the experimental room and the water temperature in the tank were determined for all conducted series. In general, the best cooling effects were achieved when the water temperature in the tank was not higher than $26.4^{\circ} \mathrm{C}$. The maximum reduction of temperature inside the experimental room was noted for the amperage $7 \mathrm{~A}$ and it was $11.7^{\circ} \mathrm{C}$.
\end{abstract}

\section{Introduction}

\subsection{Construction and operation of TE module}

Thermoelectric module (TE module) is a semiconductor-based electronic component consisted of n- and p-type doped semiconductor elements placed between two ceramic substrates. Thermoelectric elements in the module are connected electrically in series and thermally in parallel [1]. The typical construction of the TE module is shown in Fig. 1.

As a result of doping, the p-type semiconductor has fewer electrons in a given density compared to n-type. When a DC voltage is applied to the module, the electrons movement occurs. The transition of electrons from the lower energy state to the higher one requires energy supply. Therefore, on the $\mathrm{p}-\mathrm{n}$ junction, the energy from the environment is absorbed (this is the cold side of the module). The opposite situation occurs on the n-p junction where due to the transition of electrons the excess energy is released into the environment (this is

\footnotetext{
*Corresponding author: j.golebiowska@pollub.pl
} 
the hot side). This phenomenon is known as the Peltier effect and it is used in cooling process [2].

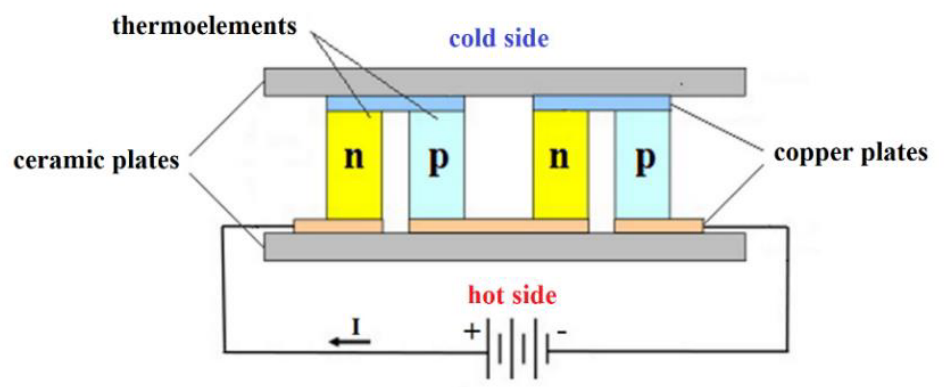

Fig. 1. Schematic construction of TE module consisted of n-type and p-type semiconductor elements [1].

Nevertheless, according to the Seebeck effect, TE modules can be also used as power generators (as a result of temperature difference between the hot and cold sides of the module) [3]. There are also other physical phenomena, such as Joule and Thomson effects as well as heat conduction, affecting the TE module performance [1, 4-6].

The cooling capacity of the TE module, understood as its ability to remove heat, depends on the electric current applied to the module, the temperatures obtained at the hot and cold sides of the module and properties of thermoelectric material. A good thermoelectric material should be characterised by high Seebeck coefficient, high electrical conductivity and low thermal conductivity. A lot of studies were conducted on this issue [7-11]. Currently, the most popular thermoelectric material is bismuth telluride $\left(\mathrm{Bi}_{2} \mathrm{Te}_{3}\right)$ characterized by ZT (dimensionless figure of merit) value of 1 - with this value of ZT the TE module can achieve only $10 \%$ of Carnot efficiency [7].

Refrigeration based on thermoelectric technology has advantages of simple use, compact size, lack of moving parts, lover levels of noise and vibration, no working fluid and small cooling capacities. The main disadvantages of thermoelectric cooling are the high cost and low energy efficiency.

\subsection{Application of TE modules for cooling}

Thermoelectric modules are often used for cooling electronic devices such i.e. processors or graphics cards, as well as in laboratory equipment due to high precision temperature control $[4,12,13]$. They are used in tourist refrigerators (also those powered by solar energy) [14].

There is also a possibility to use TE modules as components of building walls or windows in Active Building Envelopes systems, to support cooling and heating processes in the buildings $[15,16]$.

Cosnier et al. [17] presented an example of TE modules implementation in ventilation system (TE modules were integrated with the ventilation duct). Reported studies showed that a Coefficient of Performance (COP) of the system solution, understood as a ratio of useful energy gained from the system to the energy input to the system, in air cooling mode was more than 1.5 , while in heating mode was up to 2.0 .

$\mathrm{He}$ et al. [18] presented theoretical and experimental investigations of a small-scale thermoelectric cooling system, powered directly from photovoltaic panels. In the studies heat-pipe exchanger was used to reuse waste heat for applied modules for water heating purposes. The obtained COP of the system reached values above 0.45 .

Liu et al. [19] presented theoretical and experimental research of a thermoelectric solar air conditioner with the possibility of heat recovery for domestic water heating. The system 
was tested in laboratory conditions. The conducted studies showed that the designed system, operating in the cooling mode with the option of heat recovery achieved a relatively high COP value - up to 4.51 (at water temperature in the tank of $20^{\circ} \mathrm{C}$ ).

\section{Materials and methods}

\subsection{Experimental setup}

The thermoelectric cooling system (used for microscale room cooling and water heating under the laboratory conditions) was applied to an experimental room of cubature $0.125 \mathrm{~m}^{3}$. The experimental room consisted of polystyrene boards $(5 \mathrm{~cm}$ of thickness $)$ characterized by thermal conductivity coefficient of $0.034 \mathrm{~W} /(\mathrm{m} \cdot \mathrm{K})$. In the conducted research study, the cooling-type thermoelectric module was used. The basic parameters of the TE module are as following: maximum amperage $8.5 \mathrm{~A}$, maximum voltage $15.5 \mathrm{~V}$ and the maximum temperature difference between the hot and cold sides $70^{\circ} \mathrm{C}$.

The direction of the current applied to the TE module ensured the cooling effect inside the experimental room. On the cold side of the module (inside the room) the aluminum heat sinks integrated with fans was installed. On the hot side of the module the water heat exchanger was installed. Water exchanger consisted of water cooling block Thermaltake Pacific W1, insulated water tank ( $5 \mathrm{dm}^{3}$ of water volume), PVC pipes (inside diameter of $9 \mathrm{~mm}$ ) and universal water pump New Jet NJ 600.

To measure air and water temperature, voltage and intensity of current applied to the module and water flow the following devices were used:

- temperature sensors Pt500 (measuring accuracy $\pm 0.1^{\circ} \mathrm{C}$ ) within the water exchanger,

- temperature sensors Pt500 (measuring accuracy $\pm 0.1^{\circ} \mathrm{C}$ ) inside the experimental room,

- APEK AL 154 recorder connected to temperature sensors,

- digital multimeters (PeakTech),

- 1/2" single-jet dry-running water meter with pulse transmitter (BMETERS).

The scheme of applied laboratory installation allowing tests of thermoelectric module is presented in Fig. 2.

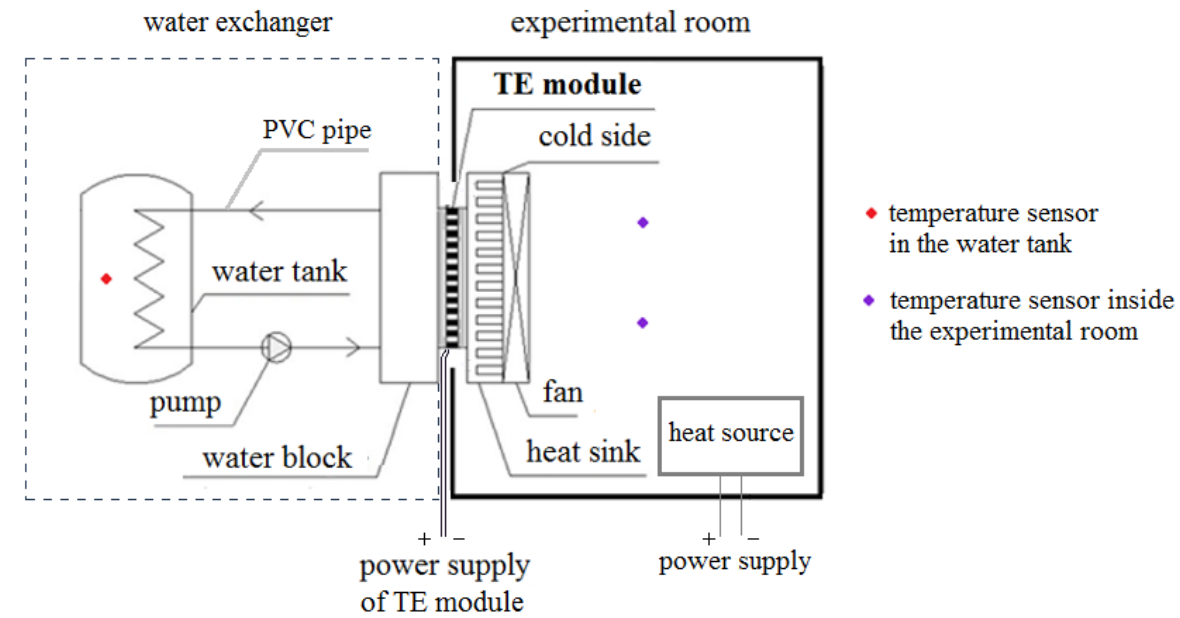

Fig. 2. Schematic construction of air cooling and water heating system with TE module. 


\subsection{Experiment assumptions}

The single measurements series lasted until the water temperature in the tank reached $55^{\circ} \mathrm{C}$ (4 A series was an exception). The mentioned above assumed value $\left(55^{\circ} \mathrm{C}\right)$ was not exceeded during all performed measurement series, for all applied values of current, because of the strength parameters of the materials used in the system and required tightness of connections of water exchanger elements.

A heat source supplied from the power grid was placed inside the experimental room in order to create an internal heat gains (see Fig. 2).

\section{Results and discussion}

\subsection{Experiment results}

The changes of air temperature inside the experimental room for different current values are presented in Fig. 3. The initial temperature of air in all cases was approx. $20.5^{\circ} \mathrm{C}$. In all cases the decrease in the air temperature to the minimal value was achieved after approx. 40 minutes of cooling process duration. The minimum measured temperature values were as follow: $13.1^{\circ} \mathrm{C}(4 \mathrm{~A}), 11.3^{\circ} \mathrm{C}(5 \mathrm{~A}), 9.5^{\circ} \mathrm{C}(6 \mathrm{~A})$ and $8.55^{\circ} \mathrm{C}(7 \mathrm{~A})$. Afterwards, the measured temperature values increased significantly. The following values of the final air temperature were observed: $20.5^{\circ} \mathrm{C}(4 \mathrm{~A}), 19.1^{\circ} \mathrm{C}(5 \mathrm{~A}), 16.7^{\circ} \mathrm{C}(6 \mathrm{~A})$ and $15.1^{\circ} \mathrm{C}(7 \mathrm{~A})$. Thus, the highest values of applied current the better cooling effects, understood as the maximum decrease in air temperature, were observed.

Air temperature in the experimental room

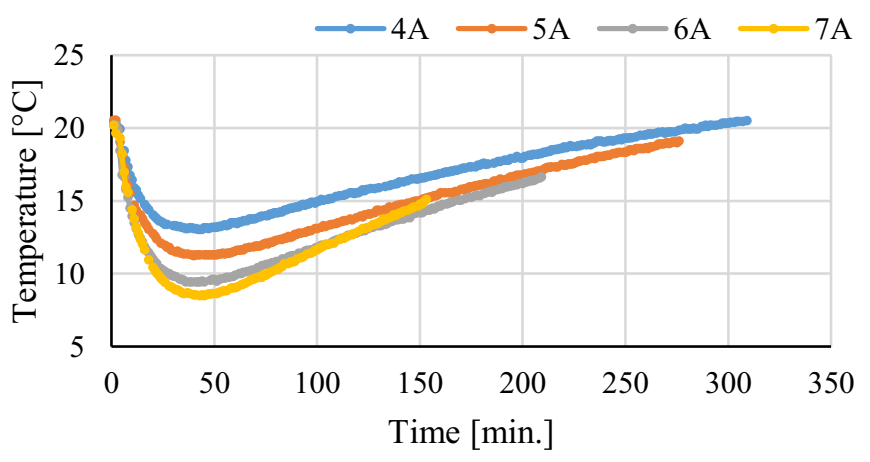

Fig. 3. Air temperature changes inside the experimental room during the tests.

However, there is a maximum possible temperature difference between the cold and the hot side of the TE module. During the experiments, the continuous increase in water temperature inside the tank (due to zero water demand) triggered the eventual increase in the air temperature inside the experimental room which can be noticed after 40 minutes of cooling process duration (see Fig. 4).

In the Fig. 4 the changes of water temperature in the tank for different currents are presented. The initial temperature of water in all analyzed series was approx. $10.5^{\circ} \mathrm{C}$. In the case of amperage $4 \mathrm{~A}$, the maximum temperature of water at the end of process was $50.5^{\circ} \mathrm{C}$ (for this value of water temperature, temperature of the air inside the experimental room was equal to the initial one). In the other cases, for amperage values $5 \mathrm{~A}, 6 \mathrm{~A}$ and $7 \mathrm{~A}$, the temperature of water at the end of series was $55^{\circ} \mathrm{C}$. The higher value of applied current, the 
faster process of water heating was noted. It results from the additional heat, described by Joule's first law, generated by current flowing through the electrical conductor of non-zero resistance (TE module) [1].

Water temerature the in water tank

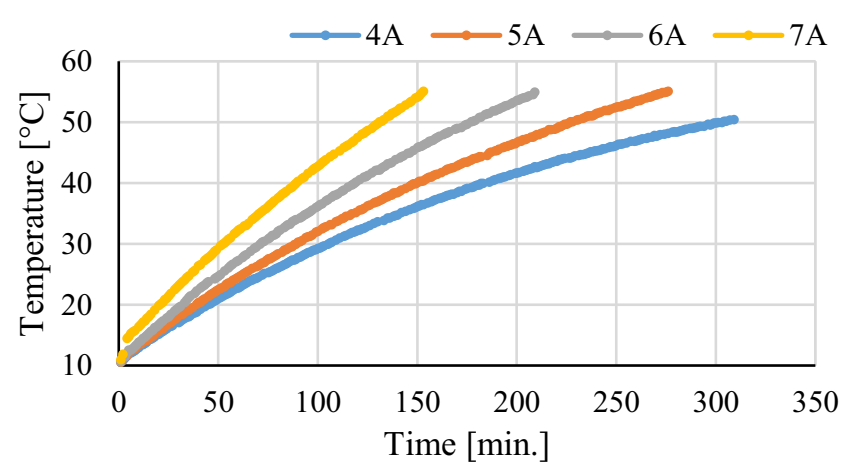

Fig. 4. Water temperature changes in the water thank during the tests

The performed statistical analysis of the obtained results of laboratory experiment showed very strong significant correlations among values of water temperature as well as air temperature for all of the applied currents (see Table 1). So, the time-related changes in measured air and water temperature values are similar in all tested cases of different currents. The distributions of studied variables tested by the Shapiro-Wilk test of normality were in all studied cases different than normal. The applied Kruskal-Wallis one-way analysis of variance supported by post-hoc multiple comparisons for both cases, i.e. temperature of water and temperature of air in the experimental room allowed to obtain different results. The KruskalWallis test for temperature of water showed that in most of the studied cases (except pair 4A and 5A) distribution functions do not differ significantly. On the other hand, the same test performed for values of temperature of air inside the experimental room demonstrated that distribution functions for all the tested currents differ significantly.

Table 1. Correlation matrix for water and air temperature measured during the experiment for different current values.

\begin{tabular}{|c|c|c|c|c|}
\hline \multirow{2}{*}{} & \multicolumn{5}{|c|}{ Water temperature in water tank } \\
\cline { 2 - 5 } & $4 \mathrm{~A}$ & $5 \mathrm{~A}$ & $6 \mathrm{~A}$ & $7 \mathrm{~A}$ \\
\hline 4A & - & 0.99990 & 0.99990 & 0.99974 \\
\hline $5 \mathrm{~A}$ & 0.99990 & - & 0.99991 & 0.99974 \\
\hline $6 \mathrm{~A}$ & 0.99990 & 0.99991 & - & 0.99966 \\
\hline $7 \mathrm{~A}$ & 0.99974 & 0.99974 & 0.99966 & - \\
\hline
\end{tabular}

\begin{tabular}{|c|c|c|c|}
\hline \multicolumn{4}{|c|}{ Air temperature in experimental room } \\
\hline $4 \mathrm{~A}$ & $5 \mathrm{~A}$ & $6 \mathrm{~A}$ & $7 \mathrm{~A}$ \\
\hline- & 0.9922 & 0.9970 & 0.9949 \\
\hline 0.9922 & - & 0.9979 & 0.9870 \\
\hline 0.9970 & 0.9979 & - & 0.9929 \\
\hline 0.9949 & 0.9870 & 0.9929 & - \\
\hline
\end{tabular}

During the experiment, correlations between the temperature values in monitored points (in the experimental room and in the water tank) were observed and presented in Fig. 5. It is visible that in all tested cases the correlations between studied values of temperature were successfully fitted to fifth degree polynomial with very high values of $\mathrm{R}^{2}(0.971-0.997)$. 

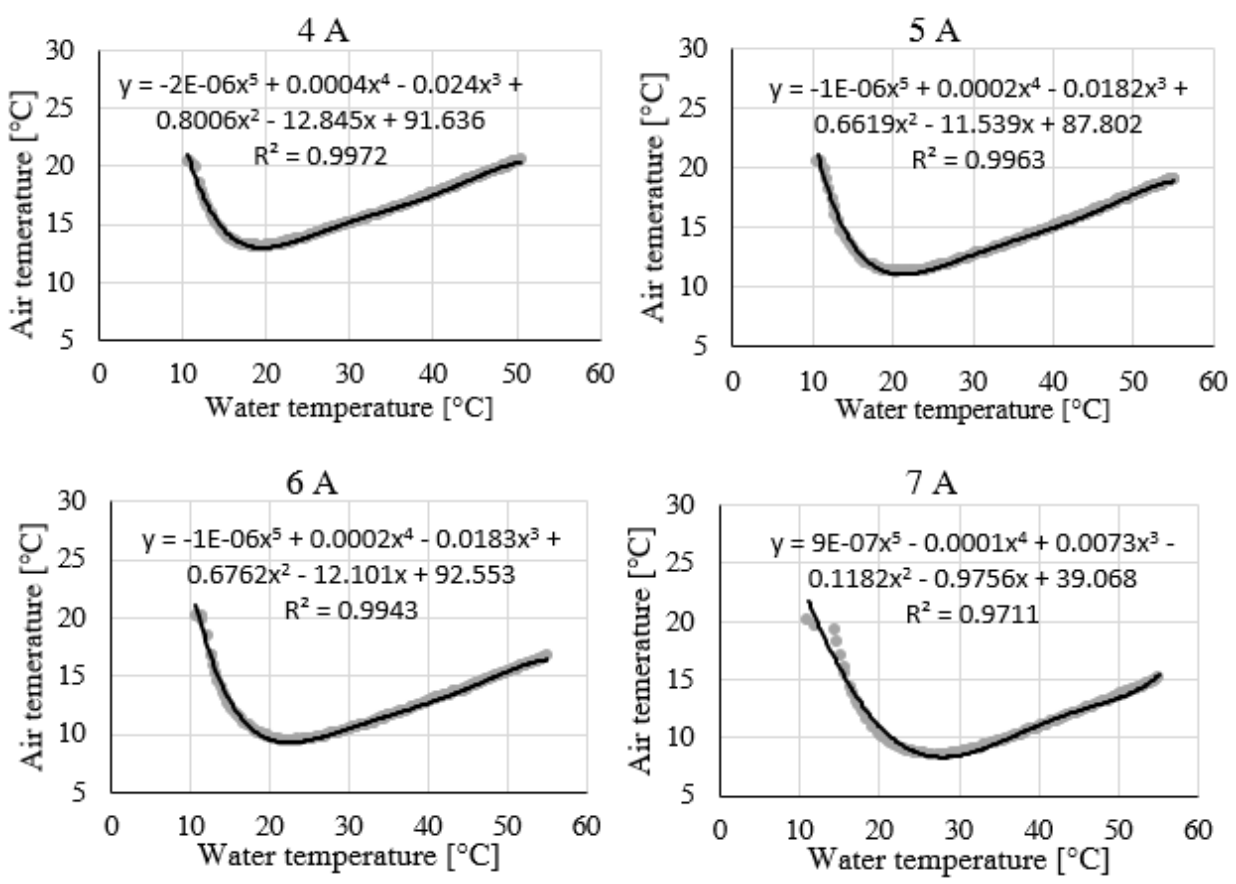

Fig. 5. Correlations between the water temperature in the water tank and air temperature inside the experimental room.

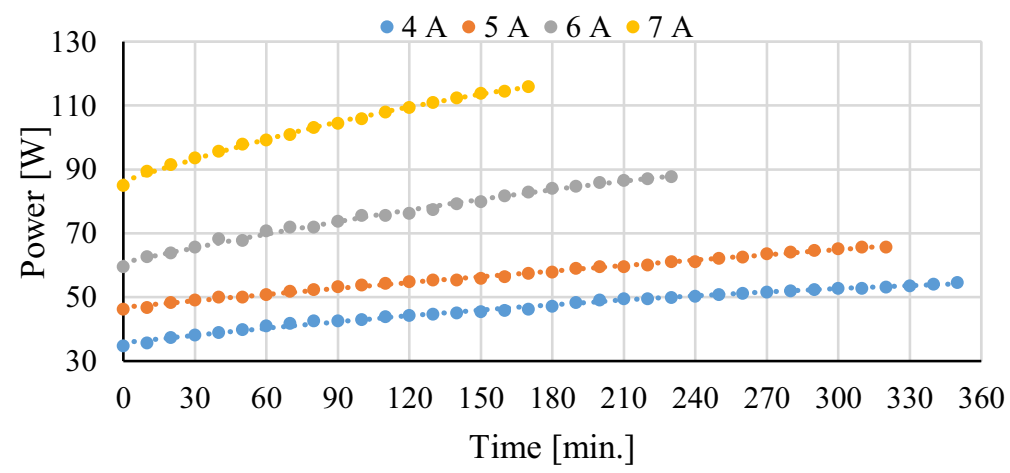

Fig. 6. Power applied to the TE module during the different series of the experiment.

During the performed experiments the paramagnets of the electric current (voltage and amperage) were monitored. These parameters were used to determine the values of power applied to the TE module (Fig. 6). There is a visible relation between cooling effects of TE module resultant from applied amperage and required power demand. Application of higher values of current allowed to obtain lower values of air temperature inside the experimental room determining better cooling effects of tested system, nevertheless the increase in power consumption was observed.

\subsection{Coefficient of performance}

On the basis of achieved results the values of the system COP were estimated for two points of experiment series: for the lowest air temperature in the room, and at the end of measuring 
series, when temperature of water was $55^{\circ} \mathrm{C}$ (for $4 \mathrm{~A} 50.5^{\circ} \mathrm{C}$ ). To determine the COP for the entire system, the following formula, suggested by the literature reports for studied type of system utilising TE module for air conditioning and water heating [18-20], was used:

$$
\mathrm{COP}=\left(\mathrm{Q}_{\mathrm{c}}+\mathrm{Q}_{\mathrm{h}}\right) /\left(\mathrm{P}_{\mathrm{TE}}+\mathrm{P}_{\mathrm{fan}}+\mathrm{P}_{\mathrm{pump}}\right)^{-1}
$$

where:

$\mathrm{Q}_{\mathrm{c}}$ - energy absorbed from the experimental room, $\mathrm{Wh}$,

$\mathrm{Q}_{\mathrm{h}}$ - energy generated on the hot side of the TE module, Wh,

$\mathrm{P}_{\mathrm{TE}}$ - energy demand for TE module powering, $\mathrm{Wh}$,

$\mathrm{P}_{\text {fan }}-$ energy demand for fan powering, $\mathrm{Wh}$,

$\mathrm{P}_{\text {pump }}$ - energy demand for pump powering, Wh.

The results of COP value calculation are presented in Table 2, as well as the energy demand for powering all devices in the system (TE module, fan and pump) and energy obtained from the system for space cooling and water heating. According to the obtained results, in all cases, the highest values of COP in the range of 1.3-1.58 were obtained after approx. $40 \mathrm{~min}$. of experiment, when the lowest values of temperature of air inside the experimental room were noted. Thus, basing on the obtained results of COP values, the tested system with TE module could be recommended to be used for preliminary water heating.

Table 2. Energy delivered to the system, energy obtained from the system and COP coefficient of the system for a given current value.

\begin{tabular}{|c|c|c|c|c|c|c|c|c|}
\hline \multirow[b]{2}{*}{$\begin{array}{c}\text { Current } \\
\text { applied } \\
\text { to the } \\
\text { TE } \\
\text { module }\end{array}$} & \multicolumn{4}{|c|}{$\begin{array}{l}\text { Min. air temp. inside the } \\
\text { experimental room }\end{array}$} & \multicolumn{4}{|c|}{ Water temp. in the water $\operatorname{tank} 55^{\circ} \mathrm{C}$} \\
\hline & $\begin{array}{c}\text { Process } \\
\text { duration } \\
\text { [min.] }\end{array}$ & $\begin{array}{c}\text { Energy } \\
\text { delivered } \\
\text { to the } \\
\text { system } \\
\text { [Wh] }\end{array}$ & $\begin{array}{l}\text { Energy } \\
\text { obtained } \\
\text { from the } \\
\text { system } \\
\text { [Wh] }\end{array}$ & $\mathrm{COP}$ & $\begin{array}{l}\text { Process } \\
\text { duration } \\
\text { [min.] }\end{array}$ & $\begin{array}{c}\text { Energy } \\
\text { delivered } \\
\text { to the } \\
\text { system } \\
\text { [Wh] }\end{array}$ & $\begin{array}{l}\text { Energy } \\
\text { obtained } \\
\text { from the } \\
\text { system } \\
\text { [Wh] }\end{array}$ & $\mathrm{COP}$ \\
\hline $4 \mathrm{~A}$ & 36 & 31.69 & 45.61 & 1.44 & 309 & 331.62 & 232.64 & 0.7 \\
\hline $5 \mathrm{~A}$ & 39 & 35.53 & 56.09 & 1.58 & 276 & 345.75 & 261.82 & 0.76 \\
\hline $6 \mathrm{~A}$ & 36 & 44.01 & 63.7 & 1.45 & 209 & 331.87 & 258.99 & 0.78 \\
\hline $7 \mathrm{~A}$ & 40 & 68.56 & 90.57 & 1.32 & 153 & 321.65 & 256.72 & 0.8 \\
\hline
\end{tabular}

\section{Conclusions}

In this paper the operation of a thermoelectric cooling system with heat recovery, powered by four applied values of current was studied. Based on the conducted experimental analysis, the following conclusions can be formulated:

- In all analyzed cases, temperature of water in the tank at the end of experiment series exceeded $50^{\circ} \mathrm{C}$. The higher value of the current applied to the TE module, the shorter the water heating time was observed.

- The observed cooling effects depended on the current applied to the TE module. In all studied cases, the best cooing results were achieved after approx. $40 \mathrm{~min}$. of the experiment, so when the temperature in the water tank was between $18.3^{\circ} \mathrm{C}$ and $26.4^{\circ} \mathrm{C}$, depended on applied current, so the tested system with TE module could be successfully used for preliminary water heating.

- In general, application of the proposed system with TE module allowed to decrease the temperature inside the experimental room by approx. $7.4-11.7^{\circ} \mathrm{C}$ regarding the minimum temperatures obtained in the experimental room and by approx. $1.5-5.1^{\circ} \mathrm{C}$ regarding to the results achieved at the end of experiment series. In all of the studied cases the observed 
differences in measured temperature for various values of applied currents were statistically significant.

This research work was supported by Polish National Science Center under the project UMO-2015/17/N/ST8/02824.

\section{References}

1. D. Enescu, E. O. Virjoghe, Renew. Sust. Energ. Rev. 38 (2014)

2. H. J. Goldsmid, Introduction to thermoelectricity (Springer, Berlin, Heidelberg, 2016)

3. D. Champier, Energy Conv. Manage. 140 (2017)

4. M. J. Huang, R. H. Yen, A. B. Wang, Int. J. Heat Mass Transfer 48, 2 (2005)

5. W. H. Chen, C. Y. Liao, C. I. Hung, Appl. Energy 89, 1 (2012)

6. H. S. Kim, W. Liu, Z. J. Ren, Appl. Phys. 118, 11 (2015)

7. D. Zhao, G. Tan, App. Therm. Eng. 66, 1 (2014)

8. B. Liao, B. Qiu, J. Zhou, S. Huberman, K. Esfarjani, G. Chen, Phys. Rev. Lett. 114, 11 (2015)

9. S. Hébert, D. Berthebaud, R. Daou, Y. Bréard, D. Pelloquin, E. Guilmeau, A. Maignan, J. Phys. Condens. Matter 28, 1 (2015)

10. O. Bubnova, Z. U. Khan, A. Malti, S. Braun, M. Fahlman, M. Berggren, X. Crispin, Nat. Rev. Mater. 10, 6 (2011)

11. N. Toshima, Synth. Met. 225 (2017)

12. V. Novak, B. Podobnik, J. Možina, Appl. Thermal Eng. 57, 1-2 (2013)

13. D. Liu, F. Y. Zhao, H. X. Yang, G. F. Tang, Energy, 83 (2015)

14. S. Su, X. Chen, J. Wang, J. Chen, Int. J. Refrig. 60 (2015)

15. R. A. Khire, A. Messac, S. Van Dessel, Int. J. Heat Mass Transfer 48, 19 (2005)

16. X. Xu, S. Van Dessel, A. Messac, Build. Environ. 42, 3 (2007)

17. M. Cosnier, G. Fraisse, L. Luo, Int. J. Refrig. 31, 6 (2008)

18. W. He, J. Zhou, J. Hou, C. Chen, J. Ji, Appl. Energy, 107 (2013)

19. Z. B. Liu, L. Zhang, G. Gong, Y. Luo, F. Meng, Energy and Build. 86 (2015)

20. Z. Liu, L. Zhang, G. Gong, Energy Convers. Manage. 87 (2014) 